\title{
Policy determinants affecting the hunger millennium development goal ${ }^{\text {tr }}$
}

\author{
Marco Antonio Palma ${ }^{\mathrm{a}, *}$, Rocio Ortiz ${ }^{\mathrm{b}}$, Carlos Alvarez-Dardet ${ }^{\mathrm{b}}$, Maria T. Ruiz ${ }^{\mathrm{b}}$ \\ a Universidad Autónoma de Yucatán, Unidad de Investigación Clínica y Epidemiológica, Avenida de los Itzaes No 498, 97200 Mérida, Yucatán Mexico \\ ${ }^{\mathrm{b}}$ Departamento de Salud Pública de la Universidad de Alicante, Observatory of Public Policies and Health, CIBERESP, Spain
}

\section{A R T I C L E I N F O}

Article history:

Available online $\mathrm{xxx}$

\section{Keywords:}

Millennium Development Goals (MDG)

Undernourishment

Developing countries

Hunger

Gini Index

\begin{abstract}
A B S T R A C T
The possible effect of Government Consumption (a component of Gross Domestic Product (GDP)) on attainment of the hunger Millennium Development Goal (MDG1) was analyzed by evaluating the effect of macroeconomic, social, demographic and policy variables on average undernourished population. Eighty-four developing countries with data available on undernourished population were included in an ecological study. Regression models were applied to explore possible determinants of Undernourished between 1990 and 2004 and consequent achievement of the projected 2004 MDG1. In 2004, 1.4\% of the overall undernourished population in the studied countries [70.16 million people] was in excess of the projected level required to meet MDG1. The multiple linear regression showed significant associations between Undernourished and poverty levels, the Gini Index, rural population and Government Consumption. The multiple logistic regression showed significant associations between achievement of projected 2004 MDG1 levels and Government Consumption and the Gini Index. The significant associations between Undernourished and Government Consumption suggest that the effects of GDP components on social conditions call for more thorough research and that policymakers such as governments and international financial institutions need to ensure that changes in distributive and redistributive policies do not negatively affect the possibility of achieving MDG1.
\end{abstract}

(c) 2009 Elsevier Ltd. All rights reserved.

\section{Introduction}

Estimates of worldwide undernourishment for 2000 are approximately 800 million people, with different distribution trends in the world's regions (Shetty, 2006). United Nations organizations have been motivating the world's governments to adopt commitments, and formulate and implement projects aimed at addressing hunger and thus meet the hunger Millennium Development Goal (MDG1) (Gillespie, 2003). To measure progress towards the MDG of halving the percentage of people suffering hunger between 1990 and 2015, the UN has proposed two indicators: 1 ) number of underweight children under 5 years of age; and 2 ) percentage of the population below the minimum dietary energy intake level [Undernourished]. These indicators were formulated and approved by the representatives of 189 countries during the Millennium Summit in 2000 as measures of progress in reducing world hunger (Sachs \& McArthur, 2005).

The Undernourished indicator encompasses a number of determining factors. Models that consider social context establish three levels: immediate factors (energy intake and health); underlying factors (food security, maternal care and environmental

\footnotetext{
Marco Palma holds a W.K Kellogg Foundation grant for PhD studies. This pape is part of his doctoral training and will be used in the PhD dissertation. The authors acknowledge the contribution of the Observatory of Public Policies and Health.

* Corresponding author. Tel.: +52 9999233297.

E-mail address: palma.solis@gmail.com (M.A. Palma).
}

services); and basic factors (in hierarchical order, Gross Domestic Product, economic structure, political and social factors) (Fernandez, Himes, \& de Onis, 2002; Jonsson, 1995; UNICEF, 1990; Wiesmann, 2006). The most frequently studied basic Undernourished determining factors include geographical distribution of population (Müller \& Krawinkel, 2005), income inequalities (Friel , Walsh, \& McCarthy, 2006), poverty (Nandy, Irving, Gordon, Subramanian, \& Smith, 2005) and macroeconomic variables, mainly Gross Domestic Product [GDP] (Darnton-Hill , Bloem, \& Chopra, 2006; Frongillo, de Onis, \& Hanson, 1997; Fay, 2005).

Political factors such as progress towards democracy (Franco, Álvarez-Dardet, \& Ruiz, 2004) and the political ideologies of governing parties (Navarro et al., 2006) have been associated with population health. These are not directly linked to the Undernourished indicator, but the assumption is that the democratic system of governance allows governments to better recognize people's needs, such as undernourishment, in developing countries. Under this assumption, increasing democratisation is one way of counteracting the negative effects on nutrition of unequal global distribution of economic resources.

Empirical studies using macroeconomic factors include GDP as an integrated variable (Asafu-Adjaye, 2004) or as separate components, such as education expenditure and types of investment (Collas-Monsod , Monsod, \& Ducanes, 2004). The conclusions reached in these studies often suggest that increased GDP improves food indicators (Milman , Frongillo, de Onis, \& Hwang, 2005), although associating GDP with health variables may have limitations in developed countries or in countries with average annual 
values of 5000 US dollars per capita or more (Wilkinson, 1992). GDP is a synthetic measure of overall economic activity used as a general epidemiological determinant under the assumption that production of national wealth is a universal factor. However, it can obscure the participation of any one of its constitutive elements in these associations because it encompasses different income and outcome groups: Domestic Consumption, Government Consumption, Gross Capital Formation, Imports and Exports. The potential usefulness of these variables in determining progress towards meeting MDG1 rests in the ability to link them to the policy decisions of governments and economically powerful groups. Jonsson (1995) explained the levels of causality that can be used to illustrate the complex relationships between the independent variables that may influence attainment of MDG1 (Fig. 1, online supplement).

Using the basic determinant factors of the Undernourished indicator, the present study objective was to use a wide range of relevant variables with known effects to analyze the effect of Government Consumption on hunger and thus explore the possible repercussions of government policies reducing resource distribution and redistribution on attainment of MDG1.

\section{Methodology}

A retrospective [1990-2004] ecological study was done using an analysis and observation unit consisting of 84 developing countries with data available on Undernourished, as well as a set of macroeconomic, social, demographic and policy variables. (Table 1, online supplement) Undernourished is defined as "the percentage of the population whose food intake falls below the minimum level of dietary energy requirements. This is also referred to as the prevalence of under nourishment, which is the percentage of the population that is undernourished" (UN, 2003). Influence of the macroeconomic, social, demographic and policy variables was analyzed as a function of average Undernourished in the 1990-2004 period, and of progress up to 2004 in meeting the 2015 goal of halving the Undernourished indicator in comparison to 1990 levels.

The macroeconomic variables were per capita GDP based on purchasing-power-parity [ppp] and the following components: General Government Final Consumption Expenditure [Government Consumption $=\mathrm{GC}$ ]; Household Consumption Expenditure [HC]; Gross Capital Formation [GCF]; Exports of goods and services [Exp.]; and Imports of goods and services [Imp.]. Government Consumption "consists of expenditure, including imputed expenditure, incurred by general government on both individual consumption goods and services and collective consumption services" (UN, 1993). The social, demographic and policy variables were: the family income inequality index [Gini]; percentage of population below the national poverty level [Poverty]; percentage of rural population [Rural]; and civil liberties and political rights index [Freedom]. The Gini index was used to analyze inequalities because it is the most frequently used summary indicator and provides a synthetic vision of inequalities, in this case, in terms of family income by country.

Data were collected from various sources: GDPppp from the IMF (2007); Undernourished and Poverty from the UN (2006); GC, HC, GCF, Exp. and Imp. from the UN (2005a); Gini data from the World Bank (2004); percentage of rural population from the World Bank (2005); world population data from the Census Bureau International Database (2008); and the Freedom Index from Freedom House. The latter is an index generated by the non-profit, independent pro-democracy organization Freedom House, which uses key indicators to calculate freedom ratings for most countries by year beginning in the 1950s. Each country report includes a section summarizing the current state of political rights and civil liberties. Each pair of political rights and civil liberties ratings is then averaged to produce an overall status: free (average ratings of 1.02.5); partially free (3.0 to 5.0); or not free (5.5 to 7.0) (Freedom House, 2008). These ratings were included in the present analysis as a proxy to explore the effects of degree of democracy on the Undernourished indicator.

A projection was made of the trend Undernourished would need to follow during the 1990-2015 period in the studied countries if they were to meet MDG1, and then the actual observed Undernourished data for each was compared to this to determine how much above or below the trend they were. The databases were used to calculate the observed tendency (expressed in percentages) in Undernourished in 1990, 1995, 2000 and 2004, corrected for country population size. The collected data for Undernourished has sufficiently complete series for 1991, 1996, 2002, 2003 and 2004 (the 1994 series only contains data for countries in transition), and these were used to generate circa data to complete those years with incomplete series. In this way, the Undernourished baseline for 1991-1996 was projected to 1990. The projected trend for Undernourished to 2015 (i.e. 50\% reduction) was calculated by dividing the observed 1990 Undernourished percentage by 2. Using the 1990 mean for Undernourished and the 2015 goal, the arithmetic projection for the Undernourished MDG trend for 1991-2014 was calculated. The percentages (for 1990-2004) were converted into absolute frequencies to calculate the differences in Undernourished for each year in the study period versus the projected level: observed Undernourished frequency for each year minus projected Undernourished MDG frequency in the same year.

To determine the influence of GC on average Undernourished (1990-2004), a linear regression was done using other independent variables as adjustment variables. Because the average Undernourished data series did not meet normality and homoscedasticity requirements, it was transformed with a natural logarithm [undernourished(ln)]. The average 1990-2004 values for GDP, GC, HC, GCF, Poverty, Rural and Gini constituted the independent continuous variables. A combined continuous variable was also built for the balance between exports and imports (E-I Balance): E-I Balance $=$ the sum of export values in a period minus the sum of import values for the same period. The nominal Freedom values were transformed into Dummy variables: free [0-0], partially free [0-1] and not free [1-0]. Introduction of all the variables into the multiple linear regression produced high colinearity, therefore, the E-I balance was eliminated because it was not significant in the simple regression.

A logistic regression was then run to understand the relationship of GC to progress towards MDG1 in 2004. The dependent variable was a stratification of the series of countries according to their advantageous or disadvantageous position for achieving this MDG, based on mean projected (MDG trend) Undernourished in 2004 for this group of countries: 0 =achieved; 1 = not achieved.

Both regression types (linear and logistic) were then run in two stages: a simple model with each independent variable and two multiple models using all the independent variables. The first model was run using only GDP and the second using its component elements. All regressions were run with a 95\% confidence interval.

To observe the value distribution of the independent macroeconomic, social, demographic and policy variables, a descriptive analysis was done of the studied countries by stratifying them according to achievement/non-achievement of the projected 2004 Undernourished MDG levels. A Mann-Whitney U test was applied at a $95 \%$ confidence level to identify significant differences.

\section{Results}

The countries included in the study represent $47 \%$ of UN member states and $76.7 \%$ of the world's population in 2004 . In 
1990, this group had an overall average of $19.5 \%$ Undernourished, and this rate decreased to 1995 compared to projected MDG levels: $17.0 \%$ observed in 1995 vs. $17.6 \%$ projected MDG. This trend reversed beginning in 1996 and began to surpass MDG levels after 2000: $15.8 \%$ observed in 2000 vs. $15.6 \%$ projected and $15.5 \%$ observed in 2004 vs. $14.1 \%$ projected. This means that in $2004,1.4 \%$ of the overall undernourished people [70.16 million] in the studied countries was in excess of the level needed to meet this MDG.

Forty-one of the studied countries had undernourished percentages lower than the $14.1 \%$ mean projected by 2004 and 43 had percentages above it (Table 1 ). With the exception of the E-I Balance and Freedom, the Mann-Whitney U test $(P<0.05)$ showed the average values for the independent variables to be significantly better in countries that had achieved the projected Undernourished MDG level for 2004.

The simple linear regression showed that all the independent variables (except E-I Balance and Freedom) were significantly associated to Undernourished $(\ln )$. The $R^{2}$ values in both multiple regressions, that with GDP as the macroeconomic variable and that with component variables of GDP, were similar (0.64 and 0.63 , respectively), and Poverty, Gini and Rural were significantly associated with Undernourished(ln). In the multiple regressions using GDP, this variable was significantly associated to 2004 MDG1 attainment whereas in that using the component variables only GC was significantly associated (Table 2 ).

In the simple logistic regression, all the macroeconomic and social variables, except E-I Balance and Freedom, were significantly associated $(P<0.05)$ with achievement of the projected 2004 Undernourished MDG level. At a $90 \% \mathrm{CI}$, Freedom would also have been significantly associated (Table 3 ). In the multiple regression using GDP, significant $(P<0.05)$ associations were found for GDP, Gini, Rural and Poverty, whereas in the regression using GDP components, only Gini and GC were significantly associated.

\section{Discussion}

Undernourished has traditionally been associated with GDP, but the results clearly suggest that the GDP component GC is a determinant variable in a context of family income inequalities, and poor and rural populations. Indeed, GC and rural population were apparently the factors that most negatively affected progress towards achievement of the hunger MDG.

The main limiting aspect in the present analysis was lack of Undernourishment indicator data from all countries worldwide.

\section{Table 1}

Average values of macroeconomic, social, demographic and policy variables for 84 countries in terms of achievement of projected 2004 MDG1 levels.

\begin{tabular}{|c|c|c|c|}
\hline \multirow[t]{2}{*}{ Variables } & & \multicolumn{2}{|l|}{ MDG1 } \\
\hline & & Achieved $^{\mathrm{a}}$ & Not achieved ${ }^{\mathrm{a}}$ \\
\hline & 9.7 & $26.2^{\dagger}$ \\
\hline \multicolumn{2}{|l|}{$\mathrm{GDP}^{\mathrm{b}}$} & 202,967 & $200,780^{\dagger}$ \\
\hline \multicolumn{2}{|l|}{$\mathrm{GC}^{\mathrm{b}}$} & 32,243 & $10,759^{\dagger}$ \\
\hline \multicolumn{2}{|l|}{$\mathrm{HC}^{\mathrm{b}}$} & 129,046 & $63,579^{\dagger}$ \\
\hline \multicolumn{2}{|l|}{$\mathrm{GCF}^{\mathrm{b}}$} & 76,977 & $31,904^{\dagger}$ \\
\hline \multicolumn{2}{|l|}{ E-I Balance ${ }^{b}$} & $-103,399$ & $-67,943$ \\
\hline \multicolumn{2}{|l|}{ Rural\% } & 42.6 & $65.1^{\dagger}$ \\
\hline \multicolumn{2}{|l|}{ Poverty\% } & 5.6 & $12.8^{\dagger}$ \\
\hline \multicolumn{2}{|l|}{ Gini $^{\mathrm{c}}$} & 39.8 & $44.2^{\ddagger}$ \\
\hline \multirow[t]{3}{*}{ Freedom } & free $^{\mathrm{d}}$ & 15 & 9 \\
\hline & partially free $^{\mathrm{d}}$ & 19 & 20 \\
\hline & not free ${ }^{d}$ & 7 & 14 \\
\hline
\end{tabular}

Mann-Whitney U: $\left({ }^{\dagger} P<0.001\right),\left({ }^{\ddagger} P<0.05\right)$.

a Average 1990-2004.

b Values (ppp) units.

c Values between 0 and 100 (zero $=$ no inequality; $100=$ maximum inequality).

d Number of countries.
Nonetheless, the studied countries account for most of the world's population, almost half of UN member states and are those experiencing the most serious problems with poverty and undernourishment. No high income countries had information on Undernourished; $33 \%$ of medium high income countries had this data; $68 \%$ of medium low income countries did and $72 \%$ of low income countries. Given this, the projections and associations generated here can be considered representative of the proportion of the world's population which most acutely experiences poverty and hunger.

The cross-sectional analytical approach is a limitation, since the impact of economic and political variables on health is best examined from a historical perspective to manifest a cumulative effect. Use of secondary information is another limitation because data quality depends on the institutional source; however, these data are the only ones available that allow testing of this hypothesis on a global level. Reverse causality is very probably not a limitation since in the multiple regressions $\mathrm{HC}$ (the variable mostly likely to be inverse related to Undernourished) lost its force of association with Undernourished and MDG1 achievement.

Some institutions have reported difficulties in achieving the Undernourished MDG (FAO, 2006; UN, 2005b). They have documented a reduction in chronic hunger (the percentage of undernourished people declined from the 1990-1992 period to the 2000-2002 period, except in Asia), but in 2002 there were still 815 million people suffering undernourishment in developing countries. Furthermore, in the most affected regions (sub-Saharan Africa and Southeast Asia) the number of undernourished people had increased by tens of millions, making the MDG all but unachievable in these regions (De Onis, Blossner, Borghi, Morris, \& Frongillo, 2004; Effah, 2006; UN, 2005b).

The results demonstrate that countries at a disadvantage for achieving the hunger MDG have low government expenditure, low household expenditure, low capital investment, unbalanced foreign trade, more poverty and limited democracy. It is also quite clear that the overall projected progress for meeting the MDG of reducing world hunger (as linked to Undernourished) by $50 \%$ between 1990 and 2015 was not met in the 1990-2004 period for the group of studied countries. The undernourished population descent curve was negatively affected in countries with higher rural population and low public expenditure for supplying goods and services to their populations, possibly indicating the importance of government distributive and redistributive functions (i.e. Government Consumption), government inability to regulate foreign trade relations and slow progress towards democracy. Incorporation of the Freedom variable in the multiple regression models did not modify the effect of other variables on Undernourished or affect achievement of MDG1; indeed, it was only significantly associated with achievement of MDG1 in the simple regression.

This analysis incorporated the principal components of GDP as separate variables, allowing for a deeper analysis of the relationship between macroeconomic factors and undernourished population, and helping to isolate those components that are clearly associated with worldwide economic development policy. Based on the results, current policies focused on reduction of state expenditure and participation in economic decisions have apparently not favoured progress towards achieving the hunger MDG.

The present results do not contradict Wilkinson's (1992) claims of the limits of the association of GDP with health because the analyses did not include countries with GDP of 5000 US dollars per capita or more. This is not to say, however, that the relationship between GC and health does not merit further study in rich countries.

A clear association was observed between a country's rural population percentage and its undernourished population, 
Table 2

Associations between average Undernourished level (1990-2004) and macroeconomic, social, demographic and policy variables in 84 countries.

\begin{tabular}{|c|c|c|c|c|c|c|c|c|c|c|}
\hline \multirow[t]{4}{*}{ Variables } & & \multicolumn{9}{|c|}{ Linear regression(CI 95\%) } \\
\hline & & \multirow{2}{*}{\multicolumn{3}{|c|}{ Simple }} & \multicolumn{6}{|l|}{ Multiple } \\
\hline & & & & & \multicolumn{3}{|l|}{ GDP } & \multicolumn{3}{|c|}{ GDP components } \\
\hline & & $B$ & $P$ & Adjusted $R^{2}$ & $B$ & $P$ & Adjusted $R^{2}$ & $B$ & $P$ & Adjusted $R^{2}$ \\
\hline$\overline{\mathrm{GDP}^{\mathrm{a}}}$ & & 0.000 & $<0.001$ & 0.54 & 0.000 & $<0.001$ & 0.64 & - & - & 0.63 \\
\hline $\mathrm{GC}^{\mathrm{a}}$ & & 0.028 & $<0.001$ & 0.38 & - & - & & -0.001 & 0.001 & \\
\hline $\mathrm{HC}^{\mathrm{a}}$ & & 0.000 & $<0.001$ & 0.48 & - & - & & -0.00007 & 0.432 & \\
\hline $\mathrm{GCF}^{\mathrm{a}}$ & & 0.000 & $<0.001$ & 0.30 & - & - & & -0.000004 & 0.951 & \\
\hline E-I Balance ${ }^{a}$ & & -7, IE-006 & 0.721 & 0.00 & - & - & & 1.3E-005 & 0.303 & \\
\hline Rural & & 0.028 & $<0.001$ & 0.38 & 0.011 & 0.019 & & 0.014 & 0.001 & \\
\hline Poverty & & 0.035 & $<0.001$ & 0.37 & 0.012 & 0.016 & & 0.016 & 0.001 & \\
\hline Gini $^{\mathrm{b}}$ & & 0.027 & 0.011 & 0.07 & 0.019 & 0.007 & & 0.014 & 0.049 & \\
\hline \multirow[t]{2}{*}{ Freedom } & partially free $\mathrm{c}^{\mathrm{C}}$ & 0.027 & 0.259 & 0.01 & -0.193 & 0.122 & & -0.177 & 0.159 & \\
\hline & not free $e^{c}$ & 0.452 & 0.098 & & -0.172 & 0.348 & & -0.149 & 0.424 & \\
\hline
\end{tabular}

\footnotetext{
a Values (ppp) units.

b Values between 0 and 100 (zero = no inequalities; $100=$ maximum inequality)
}

c Dummies $(0-0=$ free; $0-1=$ partially free; $1-0=$ not free $)$.

accompanied by strong associations with GC, poverty and family income inequality. This may support the hypothesis that the condition of having a high rural population does not in itself determine the undernourished population, but that the current economic development model has transformed this condition into a disadvantage. Therefore, its use as an adjustment variable requires special care due to possible interactions.

Government Consumption's influence on Undernourished and achievement of MDG1 in all the models apparently indicates that the effect of this variable can be obscured when GDP is used. This is supported by the fact that GC was the GDP component with the greatest influence on Undernourished and was strongly associated with achievement of MDG1. Of the independent variables with associations to Undernourished, the Gini index is important to understanding the results because it does not modify the effect of any other variable. However, in achievement of MDG1, GDP is only significantly associated when the Gini is included; without the Gini, only Poverty and Rural were significantly associated. In contrast, the Gini does not modify the effect of GC, although Poverty does. Overall, these results suggest that in a context of high poverty, high rural population and income inequality, low Government Consumption can strongly influence achievement of MDG1.

The significant associations observed here between Undernourished and Government Consumption are an alert for

Table 3

Associations between MDG1 achievement in 2004 and macroeconomic, social, demographic and policy variables in 84 countries.

\begin{tabular}{|c|c|c|c|c|c|c|c|}
\hline \multirow[t]{4}{*}{ Variables } & \multicolumn{7}{|c|}{ Logistic regression $(\mathrm{CI}=95 \%)$} \\
\hline & & \multirow{2}{*}{\multicolumn{2}{|c|}{ Simple }} & \multicolumn{4}{|c|}{ Multiple } \\
\hline & & & & \multicolumn{2}{|l|}{ GDP } & \multicolumn{2}{|c|}{ GDP components } \\
\hline & & OR & $P$ & OR & $P$ & OR & $P$ \\
\hline$\overline{\mathrm{GDP}^{\mathrm{a}}}$ & & 0.999 & $<0.001$ & 0.999 & 0.012 & - & - \\
\hline $\mathrm{GC}^{\mathrm{a}}$ & & 0.995 & $<0.001$ & - & - & 0.995 & 0.002 \\
\hline $\mathrm{HC}^{\mathrm{a}}$ & & 0.999 & $<0.001$ & - & - & 1.00 & 0.546 \\
\hline $\mathrm{GCF}^{\mathrm{a}}$ & & 0.999 & $<0.001$ & - & - & 1.00 & 0.288 \\
\hline E-I Balance ${ }^{a}$ & & 1.00 & 0.631 & - & - & 1.00 & 0.447 \\
\hline Rural\% & & 1.08 & $<0.001$ & 1.05 & 0.035 & 1.04 & 0.058 \\
\hline Poverty\% & & 1.08 & $<0.001$ & 1.02 & 0.313 & 1.02 & 0.419 \\
\hline Gini $^{b}$ & & 1.05 & 0.035 & 1.11 & 0.007 & 1.12 & 0.009 \\
\hline \multirow[t]{2}{*}{ Freedom $^{c}$} & partially free & 1.75 & 0.288 & 0.80 & 0.767 & 0.87 & 0.861 \\
\hline & not free & 3.33 & 0.055 & 1.84 & 0.430 & 2.48 & 0.273 \\
\hline
\end{tabular}

\footnotetext{
a Values (ppp) units.

b Values between 0 and 100 (zero = no inequalities; $100=$ maximum inequality).

c Dummies $(0-0=$ free; $0-1=$ partially free; $1-0=$ not free $)$.
}

researchers studying the influences of macroeconomics on health that they need to investigate the components of GDP and determine what influences they may have on human health and wellbeing. Further study is also needed on the influences of smaller elements within GDP, such as agricultural investment, tariffs on food and taxes on fertilizers, since only its principal components were studied here.

Finally, the results also serve as notice to those international organizations which influence the economic restructuring of countries (e.g. World Bank, International Monetary Fund and World Trade Organization) and to national governments, that if MDG1 is to be reached by 2015 , they must take great care that budgetary adjustments in social expenditures do not increase the risk of undernourishment in disadvantaged populations.

\section{Appendix. Supplementary material}

Supplementary data associated with this article can be found in the online version at doi:10.1016/j.socscimed.2009.02.044.

\section{References}

Asafu-Adjaye, J. (2004). Income inequality and health: a multi-country analysis International Journal of Social Economics, 31(2), 194-207.

Census Bureau. (2008). Population and household economic topics. Washington, DC IDB. [homepage on the Internet]. Available from. http://www.census.gov/cgibin/ipc/idbsprd [cited 08.01.08]

Collas-Monsod, S., Monsod, T., \& Ducanes, G. (2004). Philippines' progress towards the millennium development goals: geographical and political correlates of subnational outcomes. Journal of Human Development, 5(1), 121-149.

Darnton-Hill, I., Bloem, M., \& Chopra, M. (2006). Achieving the millennium development goals through mainstreaming nutrition: speaking with one voice. Public Health Nutrition, 9(5), 537-539.

De Onis, M., Blossner, M., Borghi, E., Morris, R., \& Frongillo, E. (2004). Estimates of global prevalence of childhood underweight in 1990 and 2015. JAMA, 291(21), 2600-2606.

Frongillo, E. A., de Onis, M., \& Hanson, K. (1997). Socioeconomic and demographic factors are associated with worldwide patterns of stunting and wasting of children. The Journal of Nutrition, 127, 2302-2309.

Effah, K. (2006). Human factor dynamics of minimizing extreme poverty and hunger in Africa. Review of Human Factor Studies, 12(1), 65-95.

FAO. (2006). El estado de la inseguridad alimentaria en el mundo 2005. FAO, ISBN 92-5-305580-4.

Fay, M. (2005). Achieving child-health-related millennium development goals: the role of infrastructure. World Development, 33(8), 1267-1284.

Fernandez, I., Himes, J., \& de Onis, M. (2002). Prevalence of nutritional wasting in populations: building explanary models using secondary data. Bulletin of the World Health Organization, 80(4), 282-291.

Franco, A., Álvarez-Dardet, C., \& Ruiz, M. T. (2004). Effect of democracy on health: ecological study. BMJ, 329, 1421-1423. 
Freedom House. (2008). Freedom in the World Country Ratings 1972-2007. Washington, DC. [homepage on the Internet]. Available from. http://www. freedomhouse.org/uploads/fiw/FIWAllScores.xls [cited 16.01.08].

Friel, S., Walsh, O., \& McCarthy, D. (2006). The irony of a rich country: issues of financial access to and availability of healthy food in the Republic of Ireland. Journal of Epidemiology and Community Health, 60(12), 1013-1019.

Gillespie, J. (2003). International organizations and the problem of child health, 1945-1960. Dynamis, 23, 115-142.

IMF. (2007). World economic outlook database, October 2007. New York, NY [homepage on the Internet]. Available from. http://www.imf.org/external/pubs/ $\mathrm{ft} /$ weo/2007/02/weodata/weoselgr.aspx [cited 05.01.08].

Jonsson, U. (1995). Towards an improved strategy for nutrition surveillance. Food and Nutrition Bulletin, 16, 102-111.

Milman, A., Frongillo, E., de Onis, M., \& Hwang, J. (2005). Differential improvement among countries in child stunting is associated with long-term development and specific interventions. The Journal of Nutrition, 135, 1415-1422.

Müller, O., \& Krawinkel, M. (2005). Malnutrition and health in developing countries. CMAJ, 173(3), 279-286.

Nandy, S., Irving, M., Gordon, D., Subramanian, S., \& Smith, G. (2005). Poverty, child undernutrition and morbidity: new evidence from India. Bulletin of the World Health Organization, 83(3), 210-216.

Navarro, V., Muntaner, C., Borrell, C., Benach, J., Quiroga, A., Rodríguez-Sanz, M. et al. (2006). Politics and health outcomes, Lancet, 368(9540), 1033-1037.

Sachs, J., \& McArthur, M. (2005). The millennium project: a plan for meeting the millennium development goals. Lancet, 365(9456), 347-353.

Shetty, P. (2006). Achieving the goal of halving global hunger by 2015 . The Proceedings of the Nutrition Society, 65(1), 7-18.
UN. (1993). System of national accounts 1993 glossary. New York, NY: UN Statistics Division. [homepage on the Internet]. Available from. http://data.un.org/ Glossary.aspx $? \mathrm{q}=$ Table $+1.2++$ Gross + domestic + product + by + expenditures + at + constant + prices [cited 05.06.05].

UN. (2003). Indicators for monitoring the millennium development goals. Definitions, rationale, concepts and sources. New York, USA: UN Publication.

UN. (2005a). Statistical database. National accounts main aggregates database. New York, NY. [homepage on the Internet]. Available from. http://unstats.un.org/ unsd/snaama/resultsBreak.asp?Slevel $=1 \&$ Cseries $=$ Code $14 \&$ Year $=2003 \% 2 \mathrm{C} 2004 \&$ IndCount $=8 \&$ Selection $=$ basic [cited 05.06.05].

UN. (2005b). UN millennium project. Millennium development goals. Inform 2005. New York: UN Public Information Department. DPI/2390.

UN. (2006). Statistical database. Millennium indicators database. New York, NY. [Internet homepage]. Available from. http://unstats.un.org/unsd/mi/mi_series_ results.asp?rowId=562 [cited 05.06.07].

UNICEF. (1990). Strategy for improved nutrition of children and women in developing countries. A UNICEF policy review No. 1. New York, USA.

WB. (2004). Measuring income inequality database. NW Washington, DC. [Internet homepage]. Available from. http://econ.worldbank.org/WBSITE/EXTERNAL/ EXTDEC/EXTRESEARCH/0,contentMDK:20699070 pagePK:64214825 piPK: 64214943 theSitePK:469382,00.html [cited 13.07.05]

WB. (2005). HNPstats - The World Bank's health, nutrition and population data platform. NW Washington, DC. [homepage on the Internet]. Available at. http:// devdata.worldbank.org/hnpstats/query/default.html [cited 20.10.07].

Wiesmann, D. (2006). Global hunger index: A basis for cross-country comparisons. Washington, DC: International Food Policy Research Institute.

Wilkinson, R. (1992). Income distribution and life expectancy. BMJ, 304, 165-168. 